\title{
Comment
}

Neuro epidemiology

Neuroepidemiology 2014;42:98-99

DOI: $\underline{10.1159 / 000356076}$

\section{Hospital-Based Study in the Context of Subarachnoid Haemorrhage Practice and Literature: Factors to Consider}

\author{
Flora Minsun Suh ${ }^{\mathrm{a}}$, Patrick M. Schweder ${ }^{\mathrm{b}}$, Edward William Mee ${ }^{\mathrm{b}}$

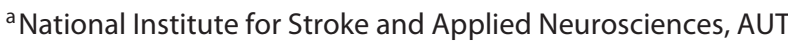 \\ University, and ${ }^{\mathrm{b}}$ Department of Neurosurgery, Auckland City \\ Hospital, Auckland, New Zealand
}

Aneurysmal subarachnoid haemorrhage (aSAH) remains a serious medical condition with high mortality and morbidity. Analysis of current clinical practices of aSAH can highlight management as well as infrastructure challenges in relation to treatment algorithms. Walendy et al. [1] have presented the current treatment trends in a nation-wide study of aSAH rates and practice in Germany over a 4-year period. A hospital remunerationbased database was used to retrieve medical information on hospitalised aSAH cases. Study methodology likely captured all hospitalised aSAH cases, though this method depends on the accuracy of data entry and coding in the remuneration system of each hospital.

In keeping with international trends of endovascular practice, the authors have shown an increase in endovascular coiling practice between 2005 and 2009. Hospitalisation rates increased, which the authors postulate is likely a result of advances in stroke care infrastructure. The observed increase may also reflect increased capturing of documented cases as a result of improvements in hospital coding practices. Recently, however, a similar epidemiological admission study carried out in the United States over a longer, 30 -year period (1979-2008) showed no change in the overall incidence rate of admissions [2]. The increased trend observed in this relatively short study should be considered in the context of such longer-term studies. Given the established hospital coding system in Germany, it would be worthwhile to continue to observe hospitalisation rates for a longer period of time.

Due to the nature of hospital-based studies, it is a challenge to relate the increased hospitalisation rate with the true incidence rate. Population-based studies (i.e. studies that include non-hospitalised cases) have suggested that an increasing proportion of stroke cases are admitted to hospitals [3]. It is unclear whether the increased hospitalisation presented by Walendy et al. [1] is a result of increases in the incidence (due to missed community cases) and proportion of hospitalisation (due to improved pre-admission care and stroke awareness), or decrease in pre-hospital deaths. The decreased smoking trends and increased management of hyperten- sion, two strong aSAH risk factors, have likely influenced aSAH incidence, pre-hospital deaths and severity of aSAH. Considering that aSAH is a relatively uncommon condition, it is especially important to identify all cases, including the non-hospitalised cases, for a comprehensive understanding of the disease. A populationbased study would help answer outstanding questions, such as these.

The differences in age-standardised hospitalisation rates among the 16 Federal States in Germany reflect significant heterogeneity in hospitalisation within a single country and point towards a likely large range of variability internationally. Better outcomes for aSAH have been observed in hospitals with greater case volumes [4]. It would be productive to more closely analyse the differences in stroke centre infrastructure to explain the observed regional differences and highlight hospital differences that contribute to better outcomes.

The authors assessed the proportion of temporary drainage of cerebrospinal fluid or permanent ventricular shunt placement according to the different treatment modalities. Clinical grade on admission and Fisher CT grading were, however, not available to compare the observed differences in shunt utilisation. The associations between age, sex and region and the rates of coiling and clipping were also assessed. Whilst age is a known variable in aneurysm treatment decision making algorithms, aSAH severity grade, aneurysm location and morphology are some of the important factors to consider when providing an analysis of population differences of these treatment modalities.

Cross-sectional and short-time spanlongitudinal epidemiological data are useful to demonstrate differences in current clinical practice. The study, which was carried out for the first time in Germany, has added to the growing knowledge base of current practice. Recently, similar studies have been carried out in the United States [2] and Scotland [5], in addition to several other studies cited by the authors. Observational studies, as this study, however, are often inconclusive regarding the effects of management on patient outcome. Extended analysis of acquired study data may investigate the effects of differential treatment practices on patient outcome, re-haemorrhage rates and procedural complications.

The authors compared mortality rates between the different treatment modalities. In-hospital mortality rate was higher in the coiling group. Although treatment modality, age and comorbidities were adjusted for, aSAH severity grade was not analysed. Severity grade on admission has been shown to be the single most important prognostic factor, and its consideration when analysing results of treatment should be emphasised $[6,7]$.

The authors have undertaken a good review of all hospitalised aSAH cases nationwide and the results add to the body of aSAH epidemiological literature. In the absence of non-hospitalised cases, the study offers a good indication of the reality of hospitalised aSAH treatments in Germany over 4 years.

\section{KARGER}

E-Mail karger@karger.com

www.karger.com/ned
2013 S. Karger AG, Basel

$0251-5350 / 13 / 0422-0098 \$ 38.00 / 0$
Flora Minsun Suh

AUT North Shore Campus, Private Bag 92006

AA253, 90 Akoranga Drive

Northcote, Auckland 0627 (New Zealand)

E-Mail flora613@gmail.com 


\section{References}

1 Walendy V, Strauss C, Rachinger J, Stang A: Treatment of aneurysmal subarachnoid haemorrhage in Germany: a nationwide analysis of the years 2005-2009. Neuroepidemiology 2014;42:90-97.

$>2$ Rincon F, Rossenwasser RH, Dumont A: The epidemiology of admissions of nontraumatic subarachnoid hemorrhage in the United States. Neurosurgery 2013;73:217-223.

- 3 Anderson CS, Carter KN, Hackett ML, Feigin V, Barber PA, Broad JB, Bonita R, Group ARCOS: Trends in stroke incidence in Auckland, New Zealand, during 1981 to 2003. Stroke 2005;36:2087-2093.

-4 Cross DT, Tirschwell DL, Clark MA, Tuden D, Derdeyn CP, Moran CJ, Dacey RGJ: Mortality rates after subarachnoid hemorrhage: variations according to hospital case volume in 18 states. J Neurosurg 2003;99:810817.
5 Macpherson KJ, Lewsey JD, Jhund PS, Gillies M, Chalmers JW, Redpath A, Briggs A, Walters M, Langhorne P, Capewell S, et al: Trends in incidence and in short term survival following a subarachnoid haemorrhage in Scotland, 1986-2005: a retrospective cohort study. BMC Neurol 2011; 11:38.

6 Connolly ESJ, Rabinstein AA, Carhuapoma JR, Derdeyn CP, Dion J, Higashida RT, Hoh BL, Kirkness CJ, Naidech AM, Ogilvy CS, et al: Guidelines for the management of aneurysmal subarachnoid hemorrhage: a guideline for healthcare professionals from the American Heart Association/American Stroke Association. Stroke 2012;43:1711-1737.

-7 Rosengart AJ, Schultheiss KE, Tolentino J, Macdonald RL: Prognostic factors for outcome in patients with aneurysmal subarachnoid hemorrhage. Stroke 2007;38:2315-2321. 